\title{
sciendo
}

\section{Decomposition of diclofenac in sewage from municipal wastewater treatment plant using ionizing radiation}

\author{
Anna Bojanowska-Czajka
}

\begin{abstract}
The decomposition of diclofenac (DCF) in sewage sludge from municipal wastewater treatment plant was investigated. It was found that adsorption of DCF on sludge is about $40 \%$. Compared to previous studies, where the degradation yield in aqueous solution was $100 \%$, in those experiments at the dose up to $5 \mathrm{kGy}$, only $50 \%$ of initial DCF concentration of $50 \mathrm{mg} \mathrm{L}^{-1}$ was decomposed in sediment and in solution over the sediment. The experiments were carried out using both gamma radiation and electron beam. It has been observed that DCF in the aqueous phase, above the sediment, was decomposed with the same efficiency using both gamma radiation and electron beam. Whereas for DCF in the sediment, a higher degradation efficiency was found when gamma radiation was applied. This is most likely due to the limited penetration depth of the electron beam into the sludge layer. It was shown that the applied peroxide addition (in a stoichiometric amount needed for complete mineralization of $50 \mathrm{mg} \mathrm{L}^{-1} \mathrm{DCF}$ ) did not cause increase in yield of DCF decomposition.
\end{abstract}

Keywords: Diclofenac $・$ Degradation efficiency $\bullet$ Electron beam $\bullet$ Gamma rays $\bullet$ Sewage sludge

\section{Introduction}

At the present time in Europe, the topic of organic pollutants is regulated by European Union (EU) Directive 2013/39. This document introduces the obligation to monitor the concentrations of selected chemical substances from the observation list in surface waters. The observation list contains substances for which the available information suggests that they may pose a risk to the EU aquatic environment. As a result of the last update in 2015, four substances from the pharmaceutical group were added to the list, of which one was diclofenac (DCF). DCF is one of the most commonly used non-steroidal anti-inflammatory drugs (NSAID), and its average consumption is $0.33 \pm 0.29 \mathrm{~g} /$ person/year [1]. For relatively large production, a large number of various types of pharmaceuti-

A. Bojanowska-Czajka

Institute of Nuclear Chemistry and Technology

Dorodna 16 Str., 03-195 Warsaw, Poland

E-mail: a.bojanowska@ ichtj.waw.pl

Received: 30 December 2020

Accepted: 8 March 2021 cals containing DCF as an active substance are available on the market without a prescription. It causes high consumption of DCF, which leads to more and more frequent detection of this drug in the environment. DCF was detected in samples from influent, effluent, and receiving streams, in surface waters, in groundwater, and even in drink-

0029-5922 () 2021 The Author(s). Published by the Institute of Nuclear Chemistry and Technology.

This is an open access article under the CC BY-NC-ND 4.0 licence (http://creativecommons.org/licences/by-nc-nd/4.0/). 
ing water, at a concentration level from $13 \mathrm{ng} \mathrm{L}^{-1}$ to $7.1 \mu \mathrm{g} \mathrm{L}^{-1}$ [2]. Some ecotoxicological studies have shown that trace amounts of DCF can accumulate in aquatic organisms, which then become toxic to other microorganisms. The available literature data show that in biological treatment processes, $100 \%$ efficiency is not achieved. Joss et al. [3] found that biological removal varies strongly from compound to compound, with no evident correlation to the chemical structure of the compound. In these conditions, they reported the partial removal of DCF from wastewater at $20-40 \%$. When the membrane bioreactor was applied for wastewater treatment, even after 26 days DCF was still present and the efficiency of decomposition was $0 \%$ [4]. Numerous studies are being carried out to find new, more efficient methods of removing these types of pollutants from water and wastewater [5-10], with the use of radiation technology [11-15]. NSAID pharmaceuticals are a relatively large group for which this research has been carried out, including DCF [16-19]. A separate problem is the sewage sludge generated in wastewater treatment plants, which may contain a wide range of harmful, toxic substances, such as heavy metals, polycyclic aromatic hydrocarbons (PAHs), polychlorinated dibenzo-p-dioxins and dibenzo-p-furans, polychlorinated biphenyls, di-phthalates, polybrominated diphenyl ethers, and residues of detergents, pharmaceuticals, personal care products, endogenous hormones, synthetic steroids, and much more. The amounts of sludge produced in the EU are very large. The 28 EU Member States generate $>10$ tons of sewage sludge (dry matter) from municipal wastewater treatment plants annually [20]. Germany, the United Kingdom, Spain, France, and Italy produce $>55-65 \%$ of the total sewage sludge amount generated [21]. Only around $40 \%$ of the sewage sludge produced in Europe is used as fertilizer in agriculture. The use of sludge in agriculture in the EU is currently regulated only by the limits of heavy metals $(\mathrm{Cd}, \mathrm{Cu}, \mathrm{Hg}, \mathrm{Ni}, \mathrm{Pb}$, and $\mathrm{Zn})$ listed in Council Directive 86/278/EEC. These documents are now over 30 years old. Several European countries have introduced more stringent requirements compared to the EU directive and have adopted concentration limits for other heavy metals, synthetic organic compounds, and microbial contamination. Poland, like Denmark and Finland, is in the group of countries that allow the use of sewage sludge after its preliminary treatment, for example, chemical treatment, heat treatment, composting, pasteurization, or fermentation. In Austria, Belgium, Germany, and the Netherlands, the use of sewage sludge in forests and green areas is completely prohibited [22]. One of the hygienization methods is the application of electron beam treatment. In this process, a small radiation dose causes deactivation of all microorganisms and their spore forms in sewage sludge [23]. As a part of this research, DCF was selected as a representative of organic pollutants present in sewage sludge. The degradation efficiency of DCF was determined with the applied radiation dose sufficient for complete hygienization.

\section{Materials and methods}

\section{Chemicals}

All chemicals applied were of the highest purity grade available and were used as received. DCF (2-(2-(2,6-dichlorophenylamino) phenyl)acetic acid) was purchased from Sigma Aldrich, Poland. Acetonitrile (used as eluent in high-performance liquid chromatography, HPLC) was purchased from J. T. Baker (USA) and hydrogen peroxide from Stanlab Sp. J. (Poland). Stock solution of DCF was prepared in deionized water Milli-Q (Millipore).

\section{Irradiation conditions}

Sewage sludge spiked with DCF to $50 \mathrm{mg} \mathrm{L}^{-1}$ was irradiated both with gamma and electron beam (EB). Gamma parameters: $\mathrm{Co}^{60}$ source Gamma Chamber with a dose rate of $2.5 \mathrm{kGy} / \mathrm{h}$. The samples were irradiated in sealed $50-\mathrm{mL}$ conical glass flasks. Dosimetry was carried out with the Fricke solution. The EB parameters were irradiation was carried out with an electron accelerator Elektronika (Russia) of beam energy $10 \mathrm{MeV}$, beam power $15 \mathrm{~kW}$, and in the following operating conditions: pulse duration $4 \mu \mathrm{s}$, break between the pulses $2.5 \mathrm{~ms}$, and dose delivered by pulse - $200 \mathrm{~Gy}$. The dose rate was estimated at $20 \mathrm{kGy} / \mathrm{s}$. Irradiated solutions were placed into polyethylene bags forming a layer of liquid on the conveyor (3-4 mm thick). DCF decomposition monitoring was carried out mainly with the use of HPLC analysis, according to our previous study [16].

\section{Extraction procedure}

Extraction procedure steps:

1. Sewage sludge spiked with DCF to $50 \mathrm{mg} \mathrm{L}^{-1}$;

2. $25 \mathrm{~mL}$ of the sample prepared in this way was centrifuged $(4500 \mathrm{rpm})$, the supernatant solution was decanted, filtered, and subjected to chromatographic analysis;

3. In the next stage, methanol was added to the centrifuged sediment to a volume of $25 \mathrm{~mL}$. The sample prepared in this way was placed in an ultrasonic bath for $15 \mathrm{~min}$;

4. After this step, the precipitate was centrifuged again (4500 rpm), and the methanol extract of the precipitate was taken, filtered, and submitted to chromatographic analysis.

\section{Results and discussion}

\section{Distribution of DCF in the sludge and solution over the sludge}

In the current regulations, it is important to develop analytical methods that will allow to determine the level of selected organic pollutants in sewage sludge at relatively low concentration and high accuracy. 


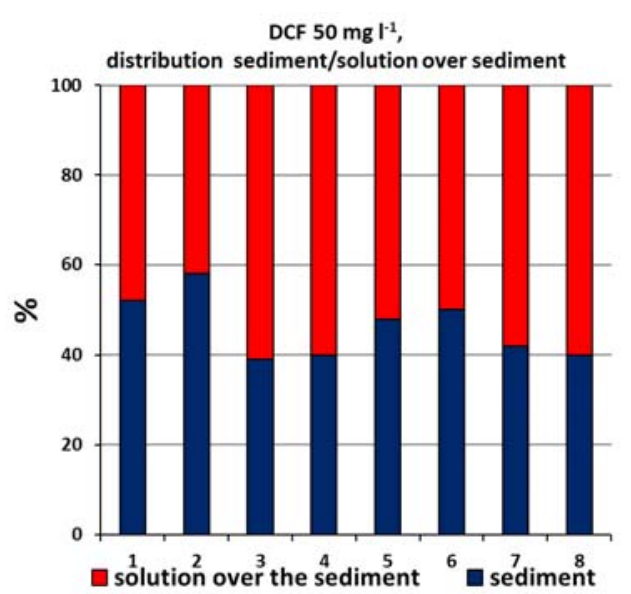

Fig. 1. Distribution ratio for $50 \mathrm{mg} \cdot \mathrm{L}^{-1} \mathrm{DCF}$ in sewage sludge.

According to various estimates, sample preparation usually takes about $70-90 \%$ of the time spent on analysis. Therefore, a great deal of effort is focused on developing reliable procedures characterized by the simplicity of both operations and equipment involved in the process. Of the extraction methods, classical techniques are still relatively most commonly used: Soxhlet extraction and ultrasound extraction [24]. Most often the sewage sludge is freeze-dried or centrifuged before the extraction stage in order to remove as much water as possible. Then extraction is carried out and the analytes are transferred to the organic phase. In the first stage, a procedure for extraction of DCF from the sewage sludge was developed to enable its chromatographic determination. The initial DCF concentration was $50 \mathrm{mg} \mathrm{L}^{-1}$. The concentration was selected in such a way as to be able to compare the obtained results with the results of earlier studies, which concerned the degradation of DCF in water under the influence of gamma radiation [16]. The data obtained for a series of eight repetitions allowed to assume that from an initial DCF concentration of $50 \mathrm{mg} \mathrm{L}^{-1}$, about $45 \%$ is adsorbed on the sediment (Fig. 1). These values were used in further studies on the DCF degradation in the sewage sludge using radiation technology both gamma and electron beam. DCF concentration in both phases, sediments and solution over sediment, was carried out according to the previously developed analytical method [16].

\section{DCF decomposition in sewage sludge}

So far the studies carried out with initial DCF concentrations in the range of $20-50 \mathrm{mg} \mathrm{L}^{-1}$ in aqueous solutions have shown that the decomposition using ionizing radiation takes place both by reaction with hydroxyl radical $(\mathrm{OH})$ and hydrated electron $\left(\mathrm{e}^{-}{ }_{\mathrm{aq}}\right)$ $[17,25]$. The reaction with the ${ }^{\circ} \mathrm{OH}$ radical occurs much faster, in the range of 9.0 [14] to $9.29 \times 10^{9}$ $\mathrm{M}^{-1} \mathrm{~s}^{-1}[25]$, than the reaction with hydrated electron (1.53). Toxicity changes using the Microtox bioindication test with an increase in the dose of ionizing radiation were also examined [17, 25]. Our previous works have shown that for an aerated aqueous solution with initial DCF concentration of $50 \mathrm{mg} \mathrm{L}^{-1}$, the total DCF degradation was observed at a dose of $4 \mathrm{kGy}$ [16]. For the degradation process carried out for natural matrices, the presence of other so-called free radical scavengers, which compete with the substances for which the degradation process is carried out, may have a significant impact. They are primarily nitrates, carbonates, chlorides, or humic compounds. Their presence most often negatively affects the efficiency of the radiolytic decomposition of selected organic pollutants, although there are known cases in which a positive effect of the presence of these compounds has been observed [26]. Previous studies have shown that in the case of an aqueous DCF solution with an initial concentration of $50 \mathrm{mg} \mathrm{L}^{-1}$, the presence of scavengers, that is, nitrates, carbonates, and humic acid at concentrations from $50 \mathrm{mg} \mathrm{L}^{-1}$ to $100 \mathrm{mg} \mathrm{L}^{-1}$ practically does not affect the efficiency of DCF decomposition in water [16]. On the other hand, Zhuan showed that for a DCF with an initial concentration of $30 \mathrm{mg} \mathrm{L}^{-1}$, the gamma-ray yield at dose $0.8 \mathrm{kGy}$ decreases from $80.8 \%$ to $62.9 \%$ in the presence of $30 \mathrm{mg} \mathrm{L}^{-1}$ humic acid [27]. As the main reason for the decrease in decomposition efficiency, the authors mention the reactions of humic acid with hydroxyl radical. In our study, sludge spiked with DCF up to $50 \mathrm{mg} \mathrm{L}^{-1}$ irradiated both the gamma and electron beam. Using the extraction procedure, degradation efficiency of DCF in the solution over the sediment and in the sediment was determined. The obtained results are presented in Fig. 2.

Compared to previous experimental data on DCF decomposition in water in the presence of scavengers $[16,27]$, the efficiency of DCF decomposition
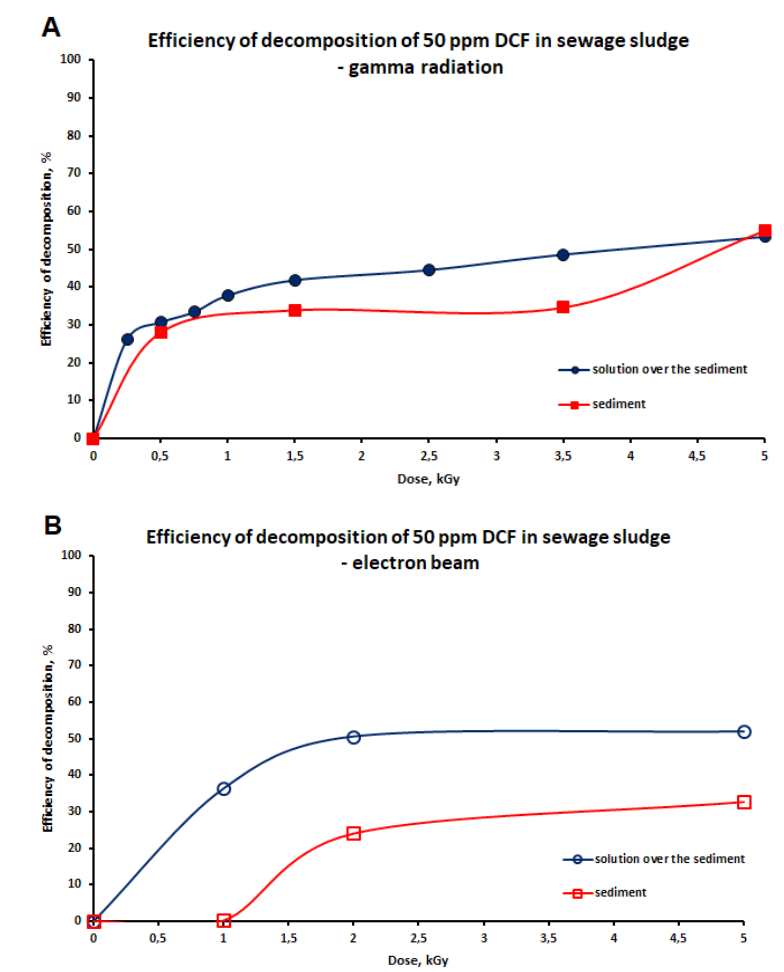

Fig. 2 Efficiency of decomposition of $50 \mathrm{mg} \mathrm{L}^{-1}$ DCF in sewage sludge under the influence of ionizing radiation: (A) gamma radiation and (B) electron beam. 
in sewage sludge is much lower. When gamma radiation is used for doses below $5 \mathrm{kGy}$, the decomposition efficiency in the sediment is slightly lower than in the solution over the sediment. Both for the sediment and for solution over the sediment the maximum efficiency achieved for $5 \mathrm{kGy}$ was only $50 \%$. Significantly greater differences were observed in the case of electron beam application; for each of the applied doses the DCF decomposition efficiency in the sediment was lower than in the solution over the sediment. The maximum efficiency value obtained for a dose of $5 \mathrm{kGy}$ was $30 \%$. The results obtained may indicate that in the case of sludge, the thickness of the irradiated sludge layer is very important; perhaps centrifugation of the sludge before irradiation would allow for a higher degree of DCF decomposition in the sludge itself.

\section{DCF decomposition in sewage sludge in the presence of $\mathrm{H}_{2} \mathrm{O}_{2}$}

To improve the efficiency of DCF decomposition in the sewage sludge using ionizing radiation, the addition of hydrogen peroxide was used. It is well known that hydrogen peroxide reacts with hydrogen atom $\mathrm{H}\left(\mathrm{k}\left(20^{\circ} \mathrm{C}\right)=2.4 \times 10^{10} \mathrm{M}^{-1} \mathrm{~s}^{-1}\right)$ and with the solvated electron $\mathrm{e}_{\mathrm{aq}}^{-}\left(\mathrm{k}\left(20^{\circ} \mathrm{C}\right)=1.5 \times 10^{7} \mathrm{M}^{-1} \mathrm{~s}^{-1}\right)$, producing an additional portion of hydroxyl radicals [28], according to the following reaction:

$$
\begin{aligned}
& \mathrm{e}^{-}{ }_{\mathrm{aq}}+\mathrm{H}_{2} \mathrm{O}_{2} \rightarrow \cdot \mathrm{OH}+\mathrm{OH}^{-} \\
& \mathrm{H}^{+}+\mathrm{H}_{2} \mathrm{O}_{2} \rightarrow \cdot \mathrm{OH}+\mathrm{H}_{2} \mathrm{O}
\end{aligned}
$$

However, the excess hydrogen peroxide in the solution can also act as a typical hydroxyl radical scavenger; the reaction takes place according to the rate $\mathrm{k}$ constant $\left(20^{\circ} \mathrm{C}\right)=3.1 \times 10^{10} \mathrm{M}^{-1} \mathrm{~s}^{-1}$ as

$$
2 \cdot \mathrm{OH}+\mathrm{H}_{2} \mathrm{O}_{2} \rightarrow 2 \mathrm{H}_{2} \mathrm{O}+\mathrm{O}_{2}
$$

It is very difficult to correctly determine the optimal amount of hydrogen peroxide needed to improve the efficiency of the radiolytic process, because it requires taking into account the numerous reactions of the generated radicals with intermediate products. In the gamma-radiation study, an addition of $840 \mu \mathrm{M}$ hydrogen peroxide was applied. The initial DCF concentration was the same at $50 \mathrm{mg} \mathrm{L}^{-1}$. It is a stoichiometric amount of hydrogen peroxide necessary to oxidize such an amount of DCF. Additionally, experiments were also performed in which the amount of added hydrogen peroxide was half of the stoichiometric amount and twice as much as the stoichiometric amount, which were $420 \mu \mathrm{M}$ and $1.68 \mathrm{mM}$, respectively. In every case for DCF deposited in the solution over the sediment, no improvement in DCF decomposition efficiency was observed compared to irradiation without hydrogen peroxide support (Fig. 3).

On the other hand, in the case of DCF deposited in the sediment, no DCF decomposition was observed in any case, but only for a dose of $5 \mathrm{kGy}$ in the presence of $1.68 \mathrm{mM} \mathrm{H}_{2} \mathrm{O}_{2}, 10 \%$ decomposi-

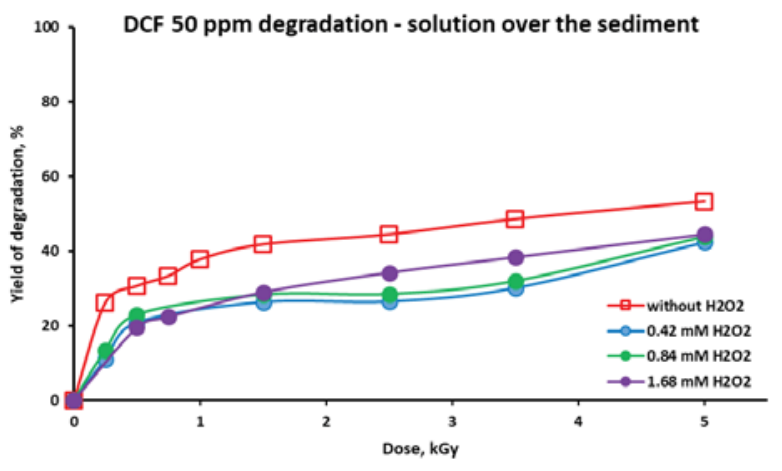

Fig. 3. Degradation of $50 \mathrm{mg} / \mathrm{L}$ DCF in sewage sludge (solution over the sediment) in the presence of $\mathrm{H}_{2} \mathrm{O}_{2}$ addition, $\square$ - without $\mathrm{H}_{2} \mathrm{O}_{2}, \bullet-0.42 \mathrm{mM} \mathrm{H}_{2} \mathrm{O}_{2}, \bullet-0.84 \mathrm{mM} \mathrm{H}_{2} \mathrm{O}_{2}$, - $1.68 \mathrm{mM} \mathrm{H}_{2} \mathrm{O}_{2}$.

tion in relation to the initial amount was observed. Additionally, based on the obtained results, it can be concluded that the applied addition of hydrogen peroxide in quantities from $0.42 \mu \mathrm{M}$ to $1.68 \mathrm{mM}$ supports DCF adsorption on the sewage sludge, preventing its decomposition under the influence of gamma radiation.

\section{Conclusions}

The use of sludge in agriculture in the EU is currently regulated only by limits for heavy metals $(\mathrm{Cd}$, $\mathrm{Cu}, \mathrm{Hg}, \mathrm{Ni}, \mathrm{Pb}$, and $\mathrm{Zn}$ ) listed in Council Directive 86/278/EEC. Several European countries have introduced more stringent requirements compared to the EU Directive and have adopted limits for concentrations of other heavy metals, synthetic organic compounds, and microbiological contamination. Therefore, for assumption of similar activities in Poland, degradation research of DCF, as a representative of organic pollutants that may be present in this type of sludge, was carried out using electron beam and gamma radiation. In accordance with the theoretical assumptions of radiation processes, it was assumed that similar results were obtained in the case of using ionizing radiation from both gamma sources and electron accelerators. In the case of gamma irradiation, for doses below $5 \mathrm{kGy}$, the degradation efficiency in the sludge is slightly lower than in the aqueous phase; for both the sludge and the water above sludge, the maximum efficiency that could be obtained for a dose of $5 \mathrm{kGy}$ was 50\%. Hygienization of sludge using an electron beam coming from the accelerator already at a dose of $5 \mathrm{kGy}$ allows for a satisfactory degree of hygienization [23]. However, this dose is insufficient to complete degradation of DCF present in the sewage sludge at a level of $50 \mathrm{mg} \mathrm{L}^{-1}$. The degradation efficiency of this pollutant for electron beam is about $30 \%$ for the sludge phase and $50 \%$ for the water phase. The addition of $\mathrm{H}_{2} \mathrm{O}_{2}$, used in the case of the gamma source research, does not lead to an increase in the degradation efficiency of DCF. On the basis of the experiments carried out, it should be expected that in the case of sludge hygienization, the use of electron beam partial degradation of pharmaceuti- 
cals present in the sewage sludge will be possible. Due to the high content of aqueous phase in the sludge, the mechanism of the process will be related to the mentioned water radiolysis.

Acknowledgment. The research was partially financed by funds granted by the National Centre for Research and Development (NCBR) - POIR 04.04-0078/17-00 "BBNawOrg" POIR.04.01.04-00-0078/17 "Zero-energy technology for the manufacturing of biologically safe organic fertilizers based on sewage sludge", the European Union's Horizon 2020 Research and Innovation Programme under Grant Agreement No. 730871 and was also supported by the Polish Ministry of Science and Higher Education, Project 3697/ H2020/2017/2 Accelerator Research and Innovation for European Science and Society (ARIES).

\section{References}

1. Acuna, V., Ginebreda, A., Mor, J. R., Petrovic, M., Sabater, S., Sumpter, J., \& Barcelo, D. (2015). Balancing the health benefits and environmental risks of pharmaceuticals: diclofenac as an example. Environ. Int., 85, 327-333. doi.org/10.1016/j.envint.2015.09.023.

2. Yan, J., Zhang, X., Lin, W., Yang, W., \& Ren, Y. (2019). Adsorption behavior of diclofenac-containing wastewater on three kinds of sewage sludge. Water Sci. Technol., 80, 717-726. doi.org/10.2166/wst.2019.315.

3. Joss, A., Keller, E., Alder, A. C., Göbel, A., McArdell, C. S., Ternes, T., \& Siegrist, H. (2005). Removal of pharmaceuticals and fragrances in biological wastewater treatment. Water Res., 39, 3139-3152. doi. org/10.1016/j.watres.2005.05.031.

4. Quintana, J. B., Weiss, S., \& Reemtsma, T. (2005). Pathway's and metabolites of microbial degradation of selected pharmaceutical and their occurrence in municipal wastewater treated by membrane bioreactor. Water Res., 39, 2654-2664. doi.org/10.1016/j. watres.2005.04.068.

5. Jallouli, N., Pastrana-Martinez, L. M., Ribeiro, A. R., Morelra, N. F. F., Faria, J. L., Hentati, O., Silva, A. M. T., \& Ksibi, M. (2018). Heterogeneous photocatalytic degradation of ibuprofen in ultrapure water, municipal and pharmaceutical industry wastewater using $\mathrm{TiO}_{2} /$ UV-LED system. Chem. Eng. J., 334, 976-984. doi. org/10.1016/j.cej.2017.10.045.

6. Aziz, K. H. H., Miessner, H., Mueller, S., Kalass, D., Moeller, D., Khorshid, J., \& Rashid, M. A. M. (2017). Degradation of pharmaceutical diclofenac and ibuprofen in aqueous solution, a direct comparison of ozonation, photocatalysis, and non-thermal plasma. Chem. Eng. J., 313, 1033-1041. doi.org/10.1016/j. cej.2016.10.137.

7. Liu, X. X., Zhou, Y. Y., Zhang, J. C., Luo, L., Yong, Y., Huang, H. L., Peng, H., Tang, L., \& Mu, Y. (2018). Insight into electro-Fenton and photo-Fenton for the degradation of antibiotics: Mechanism study and research gaps. Chem. Eng. J., 347, 379-397. doi. org/10.1016/j.cej.2018.04.142.

8. Pan, M., \& Chu, L. M. (2016). Adsorption and degradation of five selected antibiotics in agricultural soil.
Sci. Total Environ., 545, 48-56. doi.org/10.1016/j. scitotenv.2015.12.040.

9. He, X., Mezyk, S. P., Michael, I., Fatta Kassinos, D., \& Dionysiou, D. D. (2014). Degradation kinetics and mechanism of beta-lactam antibiotics by the activation of $\mathrm{H}_{2} \mathrm{O}_{2}$ and $\mathrm{Na}_{2} \mathrm{~S}_{2} \mathrm{O}_{8}$ under UV-254 nm irradiation. J. Hazard. Mat., 279, 375-383. doi. org/10.1016/j.jhazmat.2014.07.008.

10. Elomlla, E. S., \& Chaudhuri, M. (2010). Photocatalytic degradation of amoxicillin, ampicillin, and cloxacillin antibiotics in aqueous using $\mathrm{UV} / \mathrm{TiO}_{2}$ and $\mathrm{UV} /$ $\mathrm{H}_{2} \mathrm{O}_{2} / \mathrm{TiO}_{2}$ photocatalysis. Desalination, 252, 46-52. doi.org/10.1016/j.desal.2009.11.003.

11. Wang, J. L., Zhuan, R., \& Chu, L. B. (2019). The occurrence, distribution and degradation of antibiotics by ionizing radiation: An overview. Sci. Total Environ., 646, 1385-1397. doi.org/10.1016/j.scitotenv.2018.07.415.

12. Szabo, L., Toth, T., Homlok, R., Takacs, E., \& Wojnarovits, L. (2012). Radiolysis of paracetamol in dilute aqueous solution. Radiat. Phys. Chem., 81, 1503-1507. doi.org/10.1016/j.radphyschem.2011.11.036.

13. Shao, H. Y., Wu, M. H., Deng, F., Xu, G., Liu, N., Li, X., \& Tang, L. (2018). Electron beam irradiation induced degradation of antidepressant drug fluoxetine in water matrices. Chemosphere, 190, 184-190. doi. org/10.1016/j.chemosphere.2017.09.133.

14. Kimura, A., Osawa, A. M., \& Taguchi, M. (2012). Decomposition of persistent pharmaceuticals in waste water by ionizing radiation. Radiat. Phys. Chem., 81, 1508-1512. doi.org/10.1016/j.radphyschem.2011.11.032.

15. Zhang, Z. L., Chen, H., Wang, J. L., \& Zhang, Y. X. (2020). Degradation of carbamazepine by combined radiation and persulfate oxidation process. Radiat. Phys. Chem., 170, 108639-108644. doi. org/10.1016/j.radphyschem.2019.108639.

16. Bojanowska-Czajka, A., Kciuk, G., Gumiela, M., Borowiecka, S., Nałęcz-Jawecki, G., Koc, A., GarciaReyes, J. F., Solpan-Ozbay, D., \& Trojanowicz, M. (2015). Analytical, toxicological and kinetic investigation of decomposition of the drug diclofenac in waters and wastes using gamma radiation. Environ. Sci. Pollut. Res., 22, 20255-20270. doi.org/10.1007/ s11356-015-5236-6.

17. Homolok, R., Takacs, E., \& Wojnarovits, L. (2011). Elimination of diclofenac from water using irradiation technology. Chemosphere, 85, 603-608. doi. org/10.1016/j.chemosphere.2011.06.101.

18. Liu, Q., Luo, X., Zheng, Z., Zheng, B., Zhang, J., Zhao, Y., Yang, X., \& Wang, I. (2011) Factors that have an effect on degradation of diclofenac in aqueous solution by gamma ray irradiation. Environ. Sci. Pollut. Res., 18, 1243-1252. DOI: 10.1007/s11356-011-0457-9.

19. He, S. J., Wang, J. L., Ye, L. F., Zhang, Y. X., \& Yu, J. (2014). Removal of diclofenac from surface water by electron beam irradiation combined with a biological aerated filter. Radiat. Phys. Chem., 105, 104-108. doi. org/10.1016/j.radphyschem.2014.05.019.

20. Bianchini, A., Bonfigliolo, L., Pellegrini, M., \& Saccani, C. (2016). Sewage sludge management in Europe: A critical analysis of data quality. Int J. Environ. Waste Manag., 18, 226-238. DOI: 10.1504/ IJEWM.2016.080795. 
21. Collivignarelly, M. C., Abbà, A., Frattarola, A., Miino, M. C., Padovani, S., Katsoyiannis, I., \& Torretta, V. (2019). Legislation for the reuse of bosolids on agricultural land in Europe: Overview. Sustainability, 11, 6015. DOI: 10.3390/su11216015.

22. Hudcova, H., Vymazal, J., \& Rozkosny, M. (2019). Present restriction of sewage sludge application in agriculture within the European Union. Soil Water Res., 14, 104-120. doi.org/10.17221/36/2018-SWR.

23. Chmielewski, A. G., \& Sudlitz, M. (2019). 'Zero energy' electron beam technology for sludge hygienization. Nukleonika, 64, 55-63. DOI: 10.2478/ nuka-2019-0007.

24. Zuloaga, O., Navarro, P., Bizarguenaga, E., Iparraguirre, A., Vallejo, A., Olivares, M., \& Prieto, A. (2012). Overview of extraction, clean up and detection techniques for the determination of organic pollutants in sewage sludge: A review. Anal. Chim. Acta, 736, 7-29. doi.org/10.1016/j.aca.2012.05.016.

25. Yu, H., Nie, E., Xu, J., Yan, S., Cooper, W. J., \& Song, W. (2013). Degradation of diclofenac by advanced oxidation and reduction process: kinetic studies, degradation pathways and toxicity assessments. Water Res., 47, 1909-1918. doi.org/10.1016/j.watres.2013.01.016.

26. Basfar, A. A., Mohammed, K. A., Al-Abduly, A. J., \& Al-Shahvani, A. A. (2009). Radiolytic degradation of atrazine aqueous solution containing humic substances. Ecotox. Environ. Safety, 72, 948-953. DOI: 10.1016/j.ecoenv.2008.05.006.

27. Zhuan, R., \& Wang, J. (2020). Degradation of diclofenac in aqueous solution by ionizing radiation in the presence of humic acid. Sep. Purif. Technol., 234, 116079-116086. doi.org/10.1016/j.seppur.2019.116079.

28. Christensen, H., Sehested, K., \& Logager, T. (1994). Temperature dependence of the rate constant for reactions of hydrated electrons with $\mathrm{H}, \mathrm{OH}, \mathrm{H}_{2} \mathrm{O}_{2}$. Radiat. Phys. Chem., 43, 527-532. doi.org/10.1016/0969806X(94)90163-5. 